\title{
A Seasonal Field Investigation to Perceive Outdoor Thermal Comfort and Thermal Adaption at Malacca Tourist Area- A Pilot Test
}

\author{
Golnoosh Manteghi ${ }^{*}$, and Tasneem Mostofa \\ Faculty of Architecture and Built Environment (FABE) \\ INFRASTRUCTURE UNIVERSITY KUALA LUMPUR (IUKL)
}

\begin{abstract}
Season plays a key role in the development of outdoor spaces for pedestrians in hot humid cities. This research studies the influence of seasonal variations on pedestrian thermal comfort on the pedestrian level by means of meteorology and field observations of selected footpaths in the major tourist area of Malacca. This experiment was carried out on selected clear calm days indicative of each season during the development of a research project, and hourly meteorological transects from 10:00 am to 6:00 pm and questioned 200 respondents on their thermal awareness, comfort, and preferences were conducted. Adaptation, thermal comfort vote, thermal preference, age, season and hour of the day were significant non-meteorological factors, apart from meteorological information. The findings of analyzes showed that the thermal experience and expectation existed and in different seasons people changed perceptions for the outside thermal environment. Almost $80 \%$ local tourist and $55 \%$ international tourist was accepted Physiologically Equivalent Temperature (PET) range affected by the local climate and thermal adaptation. The subjective thermal sensation on physiological equivalent temperature generated an acceptable physiological equivalent temperature of $32.6^{\circ} \mathrm{C}$ to $36.8^{\circ} \mathrm{C}$ based on the seasonal variations for Malacca tourist zone in Malaysia. These findings shed light on the optimal design of outdoor spaces for increasing the utilization rate. The seasonal variation must be taken into account so that the outdoor landscape design provides more opportunities for different seasons to communicate with the atmosphere and so enhance thermal comfort and utilization.
\end{abstract}

Keywords: Seasonal Variance, Pedestrians Thermal Comfort, Physiological Equivalent Temperature (PET), Adaptive Thermal Comfort.

\section{INTRODUCTION}

To enjoy public spaces, a comfortable thermal atmosphere is important. Successful public spaces draw a large number of people who in turn are economically beneficial for companies, workers and residents and regions. Apart from that outdoor urban spaces are the outdoor places for people to walk on or engage in recreation and social activities mostly [1], [2]. However, designers and architects who want to improve urban quality through the promotion of public space utilization face difficulties in assessing the effects on human comfort or activities of different design ideas. These studies have found that the microclimate response can be unconscious but often contributes to the different use of urban space in different climates. However, detailed microclimate analysis and thermal comfort assessments have been carried out only in the last decade because of advances of techniques in the fields of urban climatology and biometeorology, such as Gothenburg, Sweden [3]; Matsudo, Japan [4]; Taichung, Taiwan [5]; Huwei, Taiwan [6]; Athens, Greece [7]; Szeged, Hungary [8]; Tianjin, China [9]; Malaysia [10]. Some research in the temperate, tropical and subtropical areas investigated whether there was a link between population numbers and thermal environment and showed the increase of space participants in public spaces with increased air temperature $(\mathrm{Ta})$ or mean radiant temperature (Tmrt) throughout the year [11]-[15]. Such studies showed that the thermal needs of people in different regions vary because of climatic adaptation, and climatic conditions in some areas influence the thermal adaptation capacity of local people. The literature reviewed notes that outside thermal comfort in an urban environment is a complex issue with numerous concerns. The evaluation process must operate at least four levels: physical, physiological, psychological, and social/behavioral [16], [17]. However, physiological adaptation to a climate is generally slow and has not been a focus of thermal comfort studies. Conversely, the impacts of psychological adaptation and behavioral adjustment on thermal comfort are significant [18]-[20]. A very few studies have examined how psychological factors influence thermal comfort, indicating that the experience at a particular season in a particular space alter how a thermal environment is perceived, and the respondent adjusts their expectations in different seasons [17]. Most cities in peninsular Malaysia experience high temperatures and humidity without significant variations all year-round. However, there is a seasonal climate change controlled by the monsoons. The monsoons reflect major changes in wind and rainfall conditions. The Monsoon Season can be categorized into two Monsoon Phases, specifically the Northeast Monsoon Season (November to March), the Southwest Monsoon Season (May to September) and the Inter Monsoon Season (April and October) with a wind 
speed of 3-7 m/s [21]. Therefore, the seasonal pattern is worth studying. This study aims to obtain an understanding of pedestrians' thermal sensations and their dynamic responses to the variation in outdoor climates at the pedestrian level for different seasons in the Malacca tourist area in Malaysia. This will provide fundamental knowledge of the thermal comfort evaluation for tourist demand in this region.

\section{RESEARCH METHOD}

Malacca city (the capital of Malacca state) has expanded over the past 10 years, especially after being designated as a UNESCO World Heritage Site in 2008. Malacca city is located in the south-western part of peninsular Malaysia $\left(2.29^{\circ} \mathrm{N}, 102.30{ }^{\circ} \mathrm{E}\right)$ and encounter high temperatures and humidity in most of the days over the year, without much fluctuation. The average temperature is $21-32^{\circ} \mathrm{C}$, and the humidity varies from $70-90 \%$. In Malaysia, March is the hottest month, rendering it preferable to understand the worst condition. However, the present study was conducted in June -July to represent the southwest monsoon period and March to represent the northeast monsoon period to obtain the average temperature, humidity, and wind speed for understanding the seasonal impact on thermal comfort range for local and international travelers. The thermal influence of the radiant fluxes was assessed by a globe thermometer. Based on globe temperature $\operatorname{Tg}\left({ }^{\circ} \mathrm{C}\right)$, the globe's emissivity $(\varepsilon \mathrm{g})$, the globe's diameter ( $\mathrm{D}$ in $\mathrm{mm}$ ), and mean radiant temperature (Tmrt in ${ }^{\circ} \mathrm{C}$ ) were calculated for forced convection and in sunshine conditions under direct solar radiation. The investigation was taken for 5 consecutive days and in two sessions. The first session of data collection was from June 30 to July 4, 2018, and the second session of data collection was from March 15, 2019, to March 19, 2019. The data collection time for both sessions was from 10:00 am to 6:00 pm.

\section{Filed Measurement Scenarios}

The Field investigation outlined seven scenarios on the base of the existing situation of the waterbody and current setting of the footpaths of the Malacca tourist area. However, in the interest of accurate quantification of the influence of the seasonal variance, wider water body pertaining to vegetation, one scenario, was omitted. As it was established that proper vegetation and waterbody reduce the air temperature and improve the outdoor thermal comfort [22]. These scenarios are tabulated in Table 1.

\section{Estimation of Meteorological data and Physiological Equivalent Temperature (PET)}

Air Temperature (Ta), Globe Temperature (Tg), Surface Temperature (Ts), Relative Humidity (RH), and Wind Speed (Va) were regularly calculated at 10-minutes interval from 10:00 am to 6:00 pm, on each survey day. The survey was started from 10:00 am as during this time, both the solar radiation (Tmrt) and $\mathrm{Ta}$, Ts are started to increase.
The instruments followed the ISO 7726 standard and kept on a tripod at $1.1 \mathrm{~m}$ above the ground. The data on $\mathrm{Ta}\left({ }^{\circ} \mathrm{C}\right)$, Ts $\left({ }^{\circ} \mathrm{C}\right), \mathrm{RH}(\%), \mathrm{Va}(\mathrm{m} / \mathrm{s})$, Tmrt $\left({ }^{\circ} \mathrm{C}\right)$, cloud cover (Octas) and water vapor pressure (VP) was calculated by $\mathrm{RH}$ conversion using the RayMan model are input for calculating the PET values. RayMan 1.2 was utilized in this work to determine the levels of PET. There is a small and almost negligible PET variance between men and women of standard height and weight $\left(\sim 0.1^{\circ} \mathrm{C}\right)$. Therefore, this work selected males who are $1.75 \mathrm{~m}$ in height, weighing $70 \mathrm{~kg}$ and are 35 years old as its calculation standard. Statistics tell us that the activity of $87 \%$ of tested peoples on the pedestrian side walkway involves walking $(\sim 0.9 \mathrm{~m} / \mathrm{s})$, which corresponds to a metabolic rate of $115 \mathrm{~W} / \mathrm{m}^{2}$ (taken as the calculation parameter). The mean clothing thermal resistance of the tested persons is $\sim 0.90$ clo.

Table-1.Description of the Scenarios

\begin{tabular}{|c|c|c|c|c|c|c|}
\hline 을 & 串 & 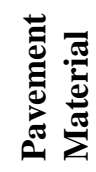 & 童 & 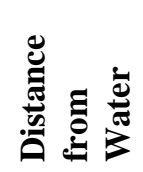 & 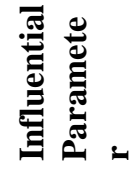 & : \\
\hline & $\begin{array}{l}\text { Scenario } \\
\text { I }\end{array}$ & Brick & $18 \mathrm{~m}$ & $0-3 m$ & Trees & $\mathrm{X}$ \\
\hline ? & $\begin{array}{l}\text { Scenario } \\
\text { III }\end{array}$ & Brick & $15 \mathrm{~m}$ & $30-35 \mathrm{~m}$ & N/A & $\sqrt{ }$ \\
\hline 인 & $\begin{array}{l}\text { Scenario } \\
\text { IV }\end{array}$ & Brick & $15 \mathrm{~m}$ & $0-3 m$ & N/A & $\sqrt{ }$ \\
\hline 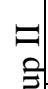 & $\begin{array}{l}\text { Scenario } \\
\text { II }\end{array}$ & $\begin{array}{l}\text { Clay } \\
\text { Tile } \\
\end{array}$ & $18 \mathrm{~m}$ & $0-3 m$ & $\begin{array}{l}\text { Min } \\
\text { Plants } \\
\end{array}$ & $\sqrt{ }$ \\
\hline อิ & $\begin{array}{l}\text { Scenario } \\
\text { VI }\end{array}$ & $\begin{array}{l}\text { Clay } \\
\text { Tile } \\
\end{array}$ & $18 \mathrm{~m}$ & $30-35 \mathrm{~m}$ & N/A & $\sqrt{ }$ \\
\hline$\exists$ & $\begin{array}{l}\text { Scenario } \\
\mathrm{V}\end{array}$ & $\begin{array}{l}\text { Clay } \\
\text { Tile } \\
\end{array}$ & $15 \mathrm{~m}$ & $0-3 m$ & N/A & $\sqrt{ }$ \\
\hline 苛 & $\begin{array}{l}\text { Scenario } \\
\text { VII }\end{array}$ & $\begin{array}{l}\text { Clay } \\
\text { Tile }\end{array}$ & $15 \mathrm{~m}$ & $30-35 \mathrm{~m}$ & N/A & $\sqrt{ }$ \\
\hline
\end{tabular}

\section{Subjective Measurement}

The questionnaire was distributed to 200 respondents selected randomly from each of the chosen sites. The questionnaire based survey was conducted parallel with the testing of the environmental variables in this study. Subsequently, the participants answered the questionnaires for expressing their subjective measurements of the present thermal environment. Furthermore, to assess the correlations among each environmental variable and the thermal comfort, the questionnaire data were evaluated and the environmental variables were calculated. The survey questionnaire was subdivided into three sections as follows: (1) Information of the subjects including the gender, age, nationality, and duration in the Malacca heritage site. (2) Clothing, food, and activity levels. (3) Based on the subjective sensation and perception of comfort concerning the climatic conditions. Besides, the thermal comfort was used to forecast the samples answers to the overall thermal environment, including air temperature, air velocity, and relative humidity. According to the above studies, the 
perception of comfortable feeling was measured on a 4 point scale having "Comfortable (0)" as the point of derivation followed by "Slightly Uncomfortable (1)", "Uncomfortable (2)", and "Very Uncomfortable (3)" [11], [23]. In this research, the perception of behavioral adjustment and the physiological acclimatization was tested using the questionnaire based on uncomfortable weather parameter with 4-point scale respectively "Wind Speed $(+1)$ ", "Air Humidity (+2)", "Air Temperature (+3)" and "None (0)" to observe how percipients are adapting the environment as there was the presence of uncomfortable parameter. Therefore, in the survey, another question was "The environment is comfortable in terms of thermal comfort with direct answers: "Not Acceptable (-1)", "Neutral (0)", "Acceptable (1)". It was used to estimate whether the subjects were satisfied with the surrounding thermal conditions.

\section{RESULTS}

\section{The Physiological Equivalent Temperature (PET) of Three Group Respectively in Southwest Monsoon Season (June-July 2018):}

The PETs of the six scenarios were analyzed and illustrated in Figures-1, 2, and 3, respectively the prolonged exposure to solar radiation led to marked fluctuations in PET during the daytime. Figures-(1-3) demonstrates that according to the recorded data, the PET values of all scenarios were $>30^{\circ} \mathrm{C}$ (upper comfort threshold).

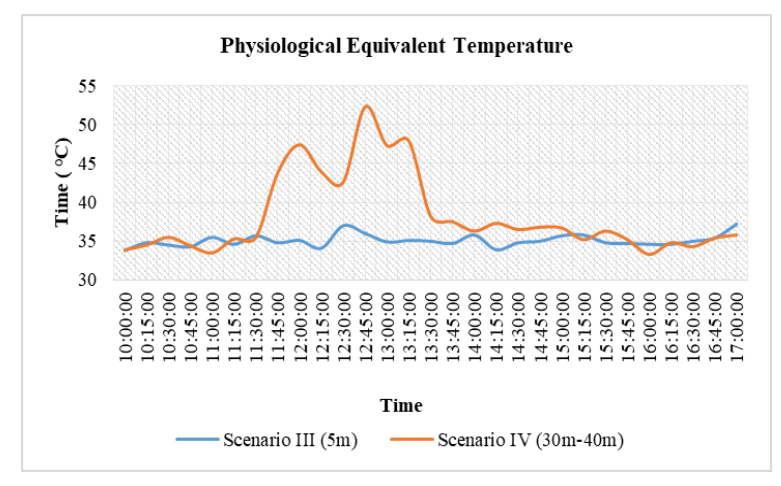

Figure-1. PET in Group I (scenarios III and IV)

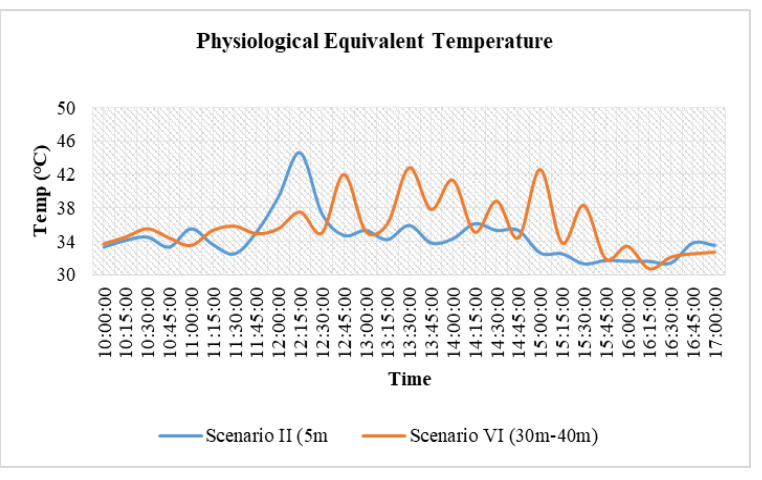

Figure-2. PET in Group II (scenarios II and VI)
From 11:40 am to $3: 00 \mathrm{pm}$, the PET values exceeded this threshold, and the thermal comfort declined remarkably. At scenario IV from Group I, adjacent to the Melaka River, the brick pavement for the pedestrian walkway, without any operative screening effectuated by the surroundings, offered minimal comfort conditions. Although scenario III was away from the Melaka River with the brick pavement similar to that of site IV, the PET values

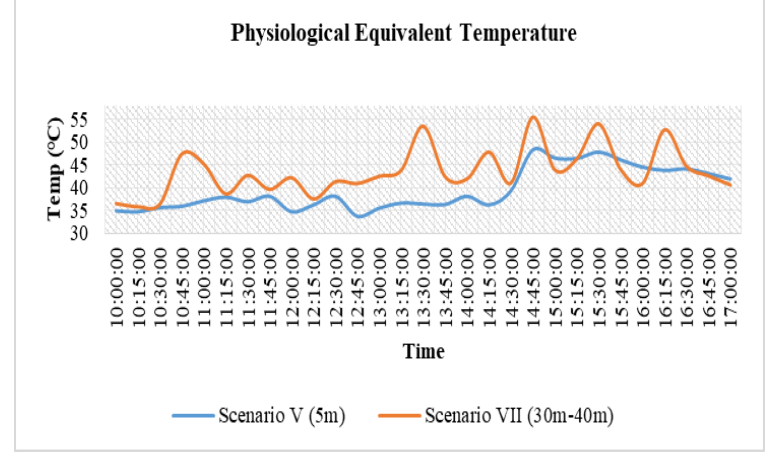

Figure-3. PET in Group III (scenarios V and VII)

were in the slightly warm range at the measurement time (mostly around noon). Nevertheless, the PET values were generally higher than the acceptable range for the tropical climate. Figure-2 shows that the values of evaluated PET of Group II where scenario II was noticeably lesser than that of scenario VI for the period of the measurement procedures. Hence, the scenario II, adjacent to the Melaka River with clay pavement for the sidewalk and rest, can easily transmit solar radiation with an evaporative cooling system with the water body. PET values at Group III were noticeably higher than that in any of the previous scenarios for the period of the measurement procedures. Furthermore, at scenario VII, PET was $40^{\circ} \mathrm{C}-44{ }^{\circ} \mathrm{C}$, which indicated an extremely hot environment from 12:00 pm to 4:30 pm. The study area was measured subsequently for 5 consecutive days at every scenario for sample different weather conditions (sunny/cloudy). Sunny days were deemed best for evaluating the meteorological parameters. Although the majority of the survey days were sunny, a cloudy day with a short drizzle period (June 1 and June 2, 2018) was also considered as the typical hot climate in Malacca is slightly overcast with direct sunlight or rain showers.

\section{The Physiological Equivalent Temperature (PET) of Three Group Respectively in Northeast Monsoon Season (March 2019)}

Figure-4 shows the calculated values of PET for both scenarios of Group I. PET values of both scenarios are usually above the maximum Comfort Limit of $30^{\circ} \mathrm{C}$ during the investigation. In Scenario III, next to the water body of Malacca, with a brick pavement for a footpath without surroundings operational screening, most of the moment, the comfort is essentially the least. It is visible that particularly around noon during the measurement moment, in scenario IV the PET values are closer to the very hot range and it was away from the Malacca water body with the 
same brick pavement for a pedestrian walkway without any effective screening generated by environ. It has been shown that PET values for both areas are above the acceptable range (less than $34^{\circ} \mathrm{C}$ ) the whole time of the assessment operation, despite the significant variations of their heat circumstances between the situations.

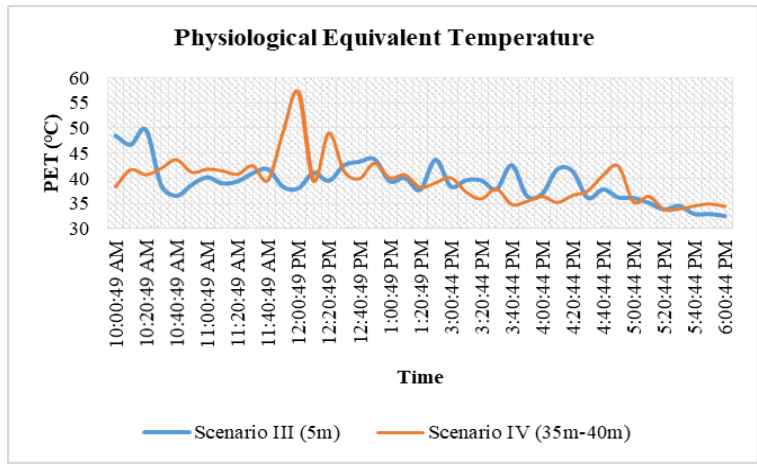

Figure-4. PET in Group I (scenarios III and IV)

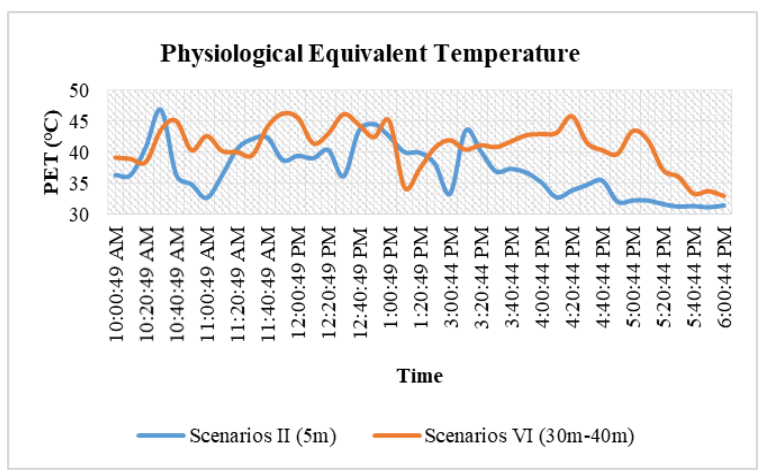

Figure-5. PET in Group II (scenarios II and VI)

It is nevertheless apparent that values of PET calculated in Scenario II (Figure-5) significantly less than the Scenario VI of group two. Consequently, Scenario II was 18 meters wide with clay pavement, close to the Malacca River, for sidewalks and rests which readily can transmit solar radiation. Thereby, approximately, the acceptable period of the thermal condition within Scenario II was obtained in the late morning and late afternoon. Nevertheless, Scenario VI was considered to higher for thermally comfortable comparing to Scenario II with the abovementioned periods. During the measurement periods, at Scenario VI, PET was gone to $44^{\circ} \mathrm{C}$ which indicated a very hot environment and from 11:20 am to 4:30 pm (Figure-6). Nonetheless, it is visible that the values of the calculated PET of group three were noticeably higher than any of the previous group for the period of the measurement procedures. During the measurement periods, at Scenario VII which is away from the water body, PET was $39{ }^{\circ} \mathrm{C}$ to $44^{\circ} \mathrm{C}$ which indicated a very hot environment and from 11:20 am to 5:00 pm. The probability was nevertheless very low at PET < $34^{\circ} \mathrm{C}$ (acceptable range) for Scenario $\mathrm{V}$ though it is close to $15 \mathrm{~m}$ wide water body, whereas, because of the high amount of solar radiation at the location, the calculated PET values were largely above the limit from 11:40 am to 4:30 p.m. Now in these fields investigate the survey days were sunny and very hot (March) because March is the hottest period for Malaysia [24].

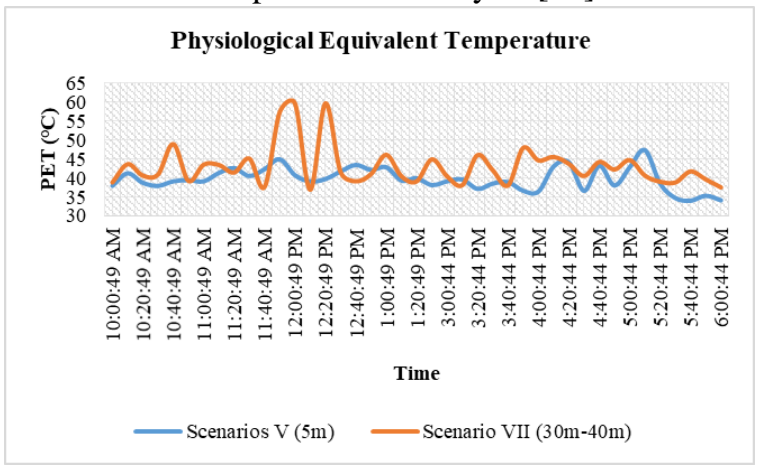

Figure-6. PET in Group III (scenarios V and VII)

\section{The Physiological Equivalent Temperature (PET) of Two Seasons}

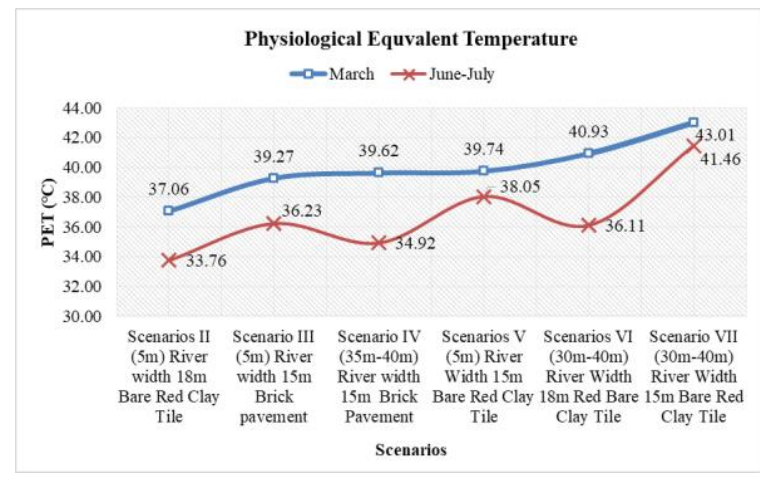

Figure-7. Average PET in six scenarios of two Seasons (June-July 2018 \& March 2019)

From Figure-7 it can be established that during the daytime, the PET values of the chosen scenarios were higher than the comfortable range in both seasons. However, in southwest monsoon season, PET was less than northeast monsoon season.

\section{Thermal Satisfaction and Preference between Local and International Respondent}

Figure- 8 to Figure-10 present the frequency distribution of sensation and preference levels between the local residents and tourists. 


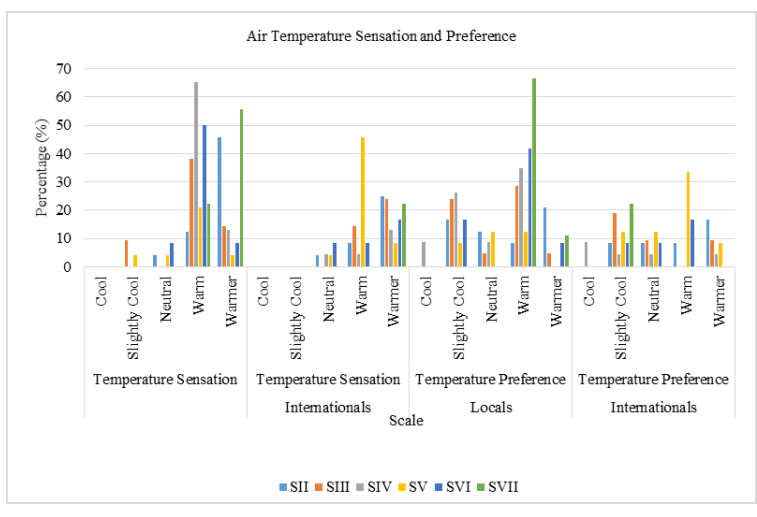

Figure-8. Air Temperature sensation and preference of respondent in six scenarios

Based on the survey findings (Figure-8), the maximum recorded percentage (76\%) was assigned to the respondents who felt warmer. The preference votes indicated the homogeneity of responses of the local and the international respondents. Figure-9 showed that 38\% Internationals and $72 \%$ locals expressed that the humidity was acceptable, while $<10 \%$ stated a neutral vote as opposed to $6 \%$ (local respondents) that thought it to be dry. On the other hand, $52 \%$ of the respondents, who were locals, preferred the humidity level to remain unchanged. According to the survey results (Figure-10), 45\% of local respondents and $50 \%$ of the international respondents declared the Va was gentle and comfortable. The outcome was in agreement with the light and variable wind conditions throughout the data collection process $(\mathrm{v}=0.13$ and $2.15 \mathrm{~m} / \mathrm{s}$, respectively). In addition, the wind preference of the individuals indicated that the prevailing gentle wind from the riverside made them feel comfortable, deeming it as improved climatic conditions. Manteghi (2015) found that $\mathrm{Va}(0.3-6.3 \mathrm{~m} / \mathrm{s})$ and orientation are critical factors in increasing the overall cooling effects of the water bodies [21], [25].

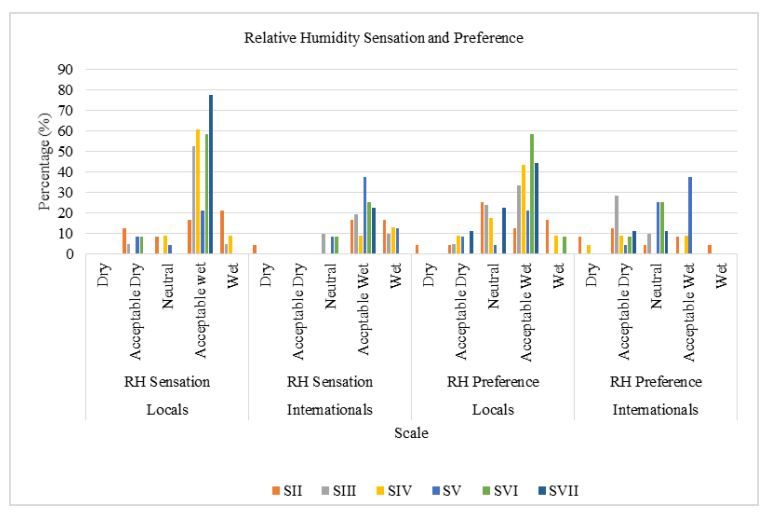

Figure-9. Relative Humidity sensation and preference of respondent in six scenarios

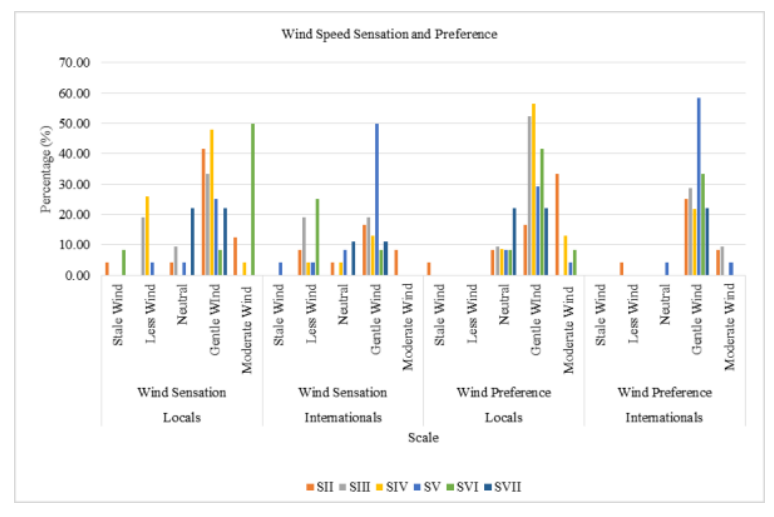

Figure-10. Wind Speed sensation and preference of respondent in six scenarios

In Figure-12 responders (mostly international tourists) considered humidity as the most un-acceptable parameter whereas locals considered air temperature. .But in Figure-11 most of them believed that the thermal environment was acceptable though it crosses the thermal comfort range in both field investigation. The respondents clarified their overall thermal comfort concerning the seasonal condition as acceptable or not acceptable and neutral.

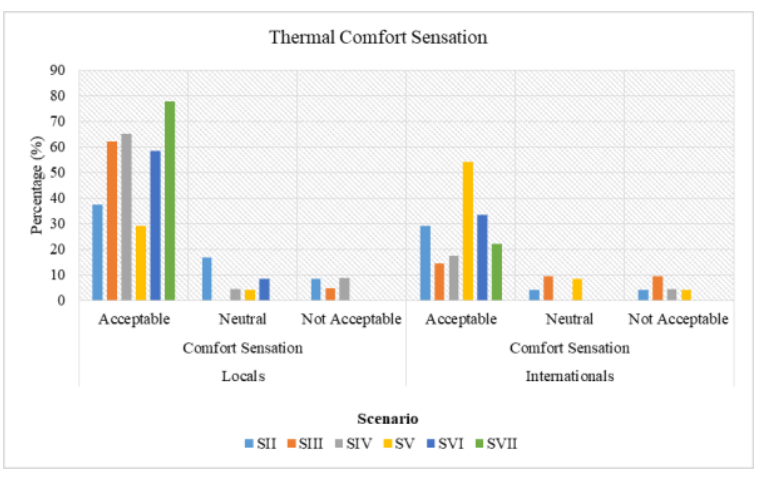

Figure-11. Thermal Comfort Sensation for Locals and Internationals in six scenarios

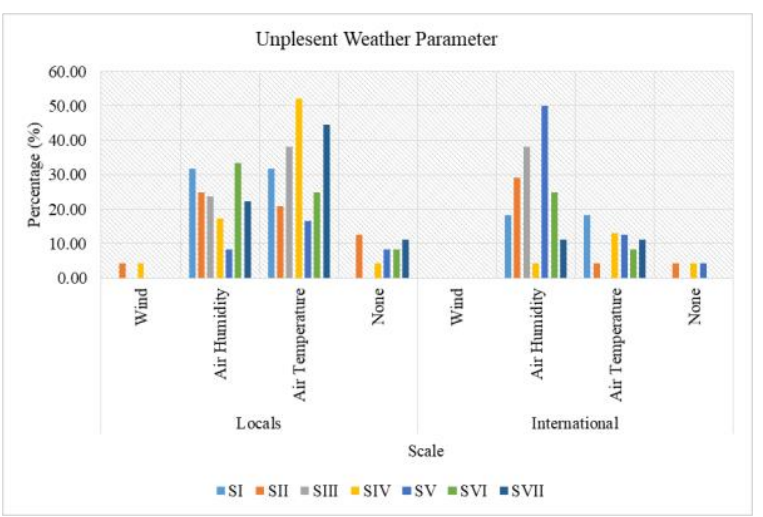

Figure-12. Unpleasant weather parameter for Locals and Internationals in six scenarios

According to the results of the pilot test, $80 \%$ of the locals and $55 \%$ of the international respondents claimed that the overall comfort condition was acceptable or 
comfortable. Intriguingly, a majority of the respective votes on the acceptable and comfortable choices were related to the afternoon period $(12: 00 \mathrm{pm}-4: 00 \mathrm{pm})$ with high heat stress. For comparing the acceptability of the thermal comfort between national and international respondents, an independent sample t-test was performed. Scores for nationals $($ Mean=2.66, Std. Deviation $=0.633)$ and internationals $(\mathrm{M}=2.64, \mathrm{SD}=0.710)$, where $\mathrm{t}=0.133$ and $\mathrm{P}=0.885$ confirmed the lack of significant differences.

\section{DISCUSSION}

It analyzed the seasonal effect of outdoor thermal comfort, compared subjective and objective comfort measures and explored how different environmental and non-environmental factors affect subjective thermal sensation. There is clear evidence that PET varies from season to season (Figure-7) although both the local and international respondents declared that they felt "comfortable" or the conditions were "acceptable". According to the adaptive comfort speculation, people react in ways to restore comfort if a transition generates discomfort [26]. This can typically be divided into three major paths: behavioral adjustment, physiological acclimatization, and psychological adaption [16]. This pilot study confirms once again the behavioral adjustment, physiological acclimatization and psychological adaption. Despite the unpleasant weather parameter (Figure-12) behavioral patterns are different and show a lag of behavioral response to the changing climate in Figure-11. As derived from the Figure-1 to Figure-6, the respondents are adaptive with the thermal comfort range despite a high PET value in every season. Again, psychological adaption including habituation, expectation, preference, and perceived control also plays an important role in occupants' thermal responses to thermal environment change. A study [27] found that psychological adaption can speed up the process of thermal adaption to the variations of the outdoor climate conditions. Another study [28] also revealed that occupants' expectations affect their ability to adapt to a non-neutral indoor climate. Some studies indicated that subjects with high perceived control tended to report more positive comfort perceptions [29]. The unique culture and living habits of people in this region may also make the results of this study differ from other studies with different regions and people [16]. Finally, we can summarize that adaptation is the capability of an individual living in a certain climatic zone to adapt to the local climate. It includes the adaptive performance of physiological regulation as well as behavioral and genetic factors. Besides, repeated thermal exposure can influence the human body to physiologically adapt to a specific thermal environment. It was reported that the low outdoor temperature could help people adapt to the coolness, and high outdoor temperature could help people adapt to the warmth [30], [31]. The results show that although the climatic conditions strongly influence the thermal sensation of users, psychological adaptation plays an important role in outdoor human thermal comfort. Results of the field investigation clarify that the respondents (both groups of local and foreigners) have become more tolerant of the warm thermal environment due to their expectation of the outdoor environment in the tropical climate.

\section{CONCLUSION}

This study presented valuable data concerning human thermal comfort with seasonal variance in outdoor spaces at the Malacca tourist area. A solution for the worst-case scenario of the microclimate is expected not to be optimum for all circumstances. On this ground, the city planners must consider the thermal adaptability of the area where a city is being planned. For example, in most days of the year in Malaysia has high temperatures and humidity, without much fluctuation, and in March a couple of very warm days. Subsequently, have to think twice about while designing and planning a city for these few days or the rest of the climatic situation. The city attracts a large number of international travellers every year, and since the tourism industry is one of the most important industries due to its economic value, the physical environment and psychological adaptations must be complementary. This study investigated the influence of micrometeorological conditions and thermal adaption on the number of pedestrians in the hot and humid regions. The outcomes of the field measurement indicated that the values of PET in the six scenarios in two seasons were higher than the comfort range defined for the tropical climate $\left(\mathrm{PET}<30^{\circ} \mathrm{C}\right)$. However, the pedestrians adjusted their perception towards thermal adaption because they have psychologically adapted with the season.

\section{REFERENCES}

[1] G. Manteghi, T. Mostofa, and Z. Hanafi, "Microclimate Field Measurements in Melaka Waterbodies," Int. J. Eng. Technol., vol. 7, no. 4.28, pp. 543-547, 2018.

[2] G. Manteghi and T. Mostofa, "Evaporative Pavements as an Urban Heat Island ( UHI ) Mitigation Strategy: A Review," Int. Trans. J. Eng. , Manag. , Appl. Sci. Technol., vol. 11, no. 1, pp. 1-15, 2020.

[3] I. Eliasson, I. Knez, U. Westerberg, S. Thorsson, and F. Lindberg, "Climate and behaviour in a Nordic city," Landsc. Urban Plan., vol. 82, no. 1-2, pp. 72-84, 2007.

[4] S. Thorsson, T. Honjo, F. Lindberg, I. Eliasson, and E.-M. Lim, "Thermal comfort and outdoor activity in Japanese urban public places," Environ. Behav., vol. 39, no. 5, pp. 660-684, 2007.

[5] T.-P. Lin, "Thermal perception, adaptation and attendance in a public square in hot and humid regions," Build. Environ., vol. 44, no. 10, pp. 2017-2026, 2009.

[6] R.-L. Hwang, T.-P. Lin, and A. Matzarakis, "Seasonal effects of urban street shading on long-term outdoor thermal comfort," Build. Environ., vol. 46, no. 4, pp. 863-870, 2011.

[7] M. Nikolopoulou and S. Lykoudis, "Use of outdoor 
spaces and microclimate in a Mediterranean urban area," Build. Environ., vol. 42, no. 10, pp. 3691-3707, 2007.

[8] N. Kántor, J. Unger, and Á. Gulyás, "Subjective estimations of thermal environment in recreational urban spaces - part 2: international comparison," Int. J. Biometeorol., vol. 56, no. 6, pp. 1089-1101, 2012.

[9] Y. L. Zeng and L. Dong, "Thermal human biometeorological conditions and subjective thermal sensation in pedestrian streets in Chengdu, China," Int. J. Biometeorol., vol. 59, no. 1, pp. 99-108, 2015.

[10] G. Manteghi, S. M. Shukri, H. Lamit, and M. Golnoosh, "Street Geometry and River Width as Design Factors to Improve Thermal Comfort in Melaka City," J. Adv. Res. Fluid Mech., vol. 58, no. 1(2019), pp. 15-22, 2019.

[11] S. B. Ali and S. Patnaik, "Thermal comfort in urban open spaces: Objective assessment and subjective perception study in tropical city of Bhopal, India," Urban Clim., vol. 24, no. October, pp. 954-967, 2018.

[12] U. Berardi, "The outdoor microclimate benefits and energy saving resulting from green roofs retrofits," Energy Build., vol. 121, pp. 217-229, 2016.

[13] K. T. Huang, T. P. Lin, and H. C. Lien, "Investigating thermal comfort and user behaviors in outdoor spaces: A seasonal and spatial perspective," Adv. Meteorol., vol. 2015, 2015.

[14] N. Nasrollahi, Z. Hatami, and M. Taleghani, "Development of outdoor thermal comfort model for tourists in urban historical areas; A case study in Isfahan," Build. Environ., vol. 125, pp. 356-372, 2017.

[15] B. Yang, T. Olofsson, G. Nair, and A. Kabanshi, "Outdoor thermal comfort under subarctic climate of north Sweden - A pilot study in Umeå," Sustain. Cities Soc., vol. 28, pp. 387-397, 2017.

[16] H. Liu, Y. Wu, B. Li, Y. Cheng, and R. Yao, Seasonal variation of thermal sensations in residential buildings in the Hot Summer and Cold Winter zone of China, vol. 140. 2017.

[17] K. Li, Y. Zhang, and L. Zhao, "Outdoor thermal comfort and activities in the urban residential community in a humid subtropical area of China," Energy Build., vol. 133, pp. 498-511, 2016.

[18] S. Coccolo, J. Kämpf, J. L. Scartezzini, and D. Pearlmutter, "Outdoor human comfort and thermal stress: A comprehensive review on models and standards," Urban Clim., vol. 18, pp. 33-57, 2016.

[19] X. Chen, P. Xue, L. Liu, L. Gao, and J. Liu, "Outdoor thermal comfort and adaptation in severe cold area: A longitudinal survey in Harbin, China," Building and Environment, vol. 143. pp. 548-560,
2018.

[20] S. Shooshtarian, P. Rajagopalan, and A. Sagoo, “A comprehensive review of thermal adaptive strategies in outdoor spaces," Sustain. Cities Soc., vol. 41, pp. 647-665, 2018.

[21] G. Manteghi, D. H. Lamit, and A. Aflaki, "Envi-Met Simulation on Cooling Effect of Melaka River," Eajournals.Org, vol. 4, no. 2, pp. 7-15, 2016.

[22] G. Manteghi, H. Bin Limit, and D. Remaz, "Water bodies an urban microclimate: A review," Mod. Appl. Sci., vol. 9, no. 6, pp. 1-12, 2015.

[23] M. Rutty and D. Scott, "Bioclimatic comfort and the thermal perceptions and preferences of beach tourists," Int. J. Biometeorol., vol. 59, no. 1, pp. 37-45, 2015.

[24] N. Ranjbar, S. Ahmad, N. Yusoff, and A. Hagishima, "Time Series Data Analysis of Household Electricity Usage during El-Nino in Malaysia," vol. 56, no. May 2016, pp. 379-384, 2017.

[25] G. Manteghi, "Influence of Street Orientation and Distance To Water Body on Microclimate Temperature Distribution In Tropical Coastal City of Malacca," Int. J. Appl. Environ. Sci. ISSN, vol. 10, no. 2, pp. 973-6077, 2015.

[26] M. Humphreys et al., ADAPTIVE THERMAL COMFORT: FOUNDATIONS AND ANALYSIS. 2016.

[27] W. Liu, H. Huangfu, J. Xiong, and Q. Deng, "Feedback effect of human physical and psychological adaption on time period of thermal adaption in naturally ventilated building," Build. Environ., vol. 76, pp. 1-9, 2014.

[28] M. Luo et al., "The dynamics of thermal comfort expectations: The problem, challenge and impication," Build. Environ., vol. 95, pp. 322-329, 2016.

[29] M. Luo, B. Cao, W. Ji, Q. Ouyang, B. Lin, and Y. $\mathrm{Zhu}$, "The underlying linkage between personal control and thermal comfort: psychological or physical effects?," Energy Build., vol. 111, pp. 56-63, 2016.

[30] J. A. Rodríguez Algeciras, H. Coch, G. De la Paz Pérez, M. Chaos Yeras, and A. Matzarakis, "Human thermal comfort conditions and urban planning in hot-humid climates-The case of Cuba," Int. J. Biometeorol., vol. 60, no. 8, pp. 1151-1164, 2016.

[31] C. K. C. Lam, M. Loughnan, and N. Tapper, "Visitors' perception of thermal comfort during extreme heat events at the Royal Botanic Garden Melbourne," Int. J. Biometeorol., vol. 62, no. 1, pp. 97-112, 2018. 